\title{
Synthetic and crystallographic studies of bicyclo[3.3.1]nonanes derivatives: From strong to weak hydrogen bonds and the stereochemistry of network formation
}

\author{
Carl-Johan Wallentin ${ }^{\mathrm{a}}$, Edvinas Orentas ${ }^{\mathrm{b}}$, Magnus T. Johnson ${ }^{\mathrm{a}}$, Nikoletta B. Bathori ${ }^{\mathrm{c}}$, Eugenijus \\ Butkus $^{* b}$, Ola F. Wendt ${ }^{* a}$, Kenneth Wärnmark* ${ }^{* a}$, and Lars Öhrström*d
}

Received (in XXX, XXX) 1st January 2007, Accepted 1st January 2007

First published on the web 1st January 2007

DOI: $10.1039 / \mathbf{b 0 0 0 0 0 0 x}$

The syntheses and crystal structures of four unsaturated bicyclo[3.3.1]nonane derivatives 10 containing various functionalities are presented and their intermolecular interactions examined.

The impact of unsaturation on crystal structures and intermolecular networks of the six membered rings were found to be significant compared to the saturated analogues. Thus, unsaturated diol rac$\mathbf{1}$, in striking contrast to its saturated analogue $\mathrm{rac}-\mathbf{6}$, does not crystallise with spontaneous resolution. The hydrogen bonds in the starting bicyclononane diene diol $\mathrm{rac}-\mathbf{1}$, and the weaker

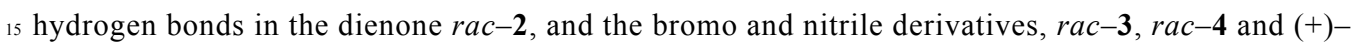
4 respectively, were found significant for the overall structure. The two bromine atoms in $\mathrm{rac}-3$ have significant halogen-halogen interactions. In several structures $2 \mathrm{D}$ nets can be identified and overall structures can be interpreted as close packing of these layers. The crystal structures were also subject to independent analysis by Hirshfeld surfaces, and this method provided additional

20 insights, especially for the structural role of the unsaturation. The possible relation between chiral networks and conglomerate formation is discussed.

\section{Introduction}

Synthetic and structural studies of the bicyclo[3.3.1]nonanes (BCN's) (structure A, Figure 1) have attracted much interest 25 for several reasons. First, this framework is a common motif in many natural and biologically active compounds. ${ }^{1}$ This includes potential therapeutics for Alzheimer's disease such as Garsubellin A (structure B, Figure 1$)^{2}$ and Huperzine A (structure C, Figure 1). ${ }^{3}$

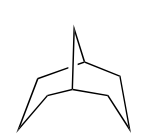

A

30

Fig. 1. The bicyclo[3.3.1]nonane framework (A), natural products containing this frame work: garsubellin A (B), huperzine A $(\mathbf{C})$.

Second, the stereochemical multiplicity of this semi-rigid framework allows functional groups to be placed in defined 35 spatial positions. An important feature of this ring system is that it consists of two cyclohexane rings which both can adopt either a chair or a boat conformation. ${ }^{1}$ The framework may also be chiral by virtue of the molecular topology only. The unique molecular shape of the $\mathrm{BCN}$ framework when 40 substituted with suitable hydrogen-bond donors and acceptors or other groups capable of generating supramolecular synthons, has been successfully employed in the selfassembly of a wide range of supramolecular structures and inclusion complexes with various guest molecules. ${ }^{4}$

45 Some hydroxyl derivatives of this ring skeleton, the so called "tubuland diols", give controllable crystal structures with a variety of inclusion guests, illustrating the potential of BCN's in crystal engineering. ${ }^{5}$ We recently showed how an analysis of the network topology of $\mathrm{BCN}$ diols can provide a ${ }_{50}$ general way of both understanding and comparing these structures. ${ }^{6 a}$ Also in the case of less strongly interacting entities, a network analysis approach ${ }^{7}$ can be profitable, although more caution is recommended when the structure directing power of, for example, weak hydrogen bonds are ${ }_{55}$ discussed. Nevertheless, we have recently prepared organometallic systems where such interactions consistently give rise to 3D-nets and large, solvent filled channels. ${ }^{8}$

An additional aspect that renders the $\mathrm{BCN}$ interesting from a stereochemical point of view is that some of these 60 aforementioned diols crystallise as conglomerates, i.e. they form homochiral crystals from a racemic mixture in solution.

In this work we report on our continued exploration of the synthetic and structural chemistry of the BCN framework, compounds 1-4, see Figure 2. We are particularly interested in ${ }_{65}$ the effect that unsaturation in the $\mathrm{BCN}$ framework may have on crystal structures and networks, since this renders the six membered rings significantly flattened and the BCN skeleton more conformationally restrained. 

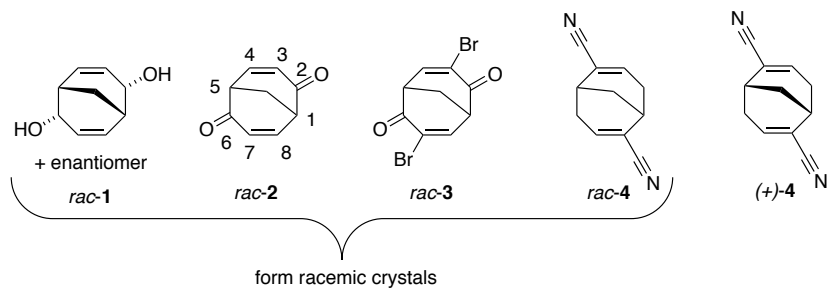

Fig. 2. The compounds 1-4 discussed in this investigation. For each racemic structure, one enantiomer is shown.

5 We furthermore explore what effect the potential, weak, hydrogen bonds introduced by the unsaturation, will have on the solid state structure of the so formed compounds $\mathrm{rac}-\mathbf{1}$, $r a c-2, r a c-3, r a c-4$, and (+)-4. It is worth noticing that the introduction of a bromine atom in the unsaturated $\mathrm{BCN}$ 10 skeleton, $r a c-\mathbf{3}$, also introduces another intermolecular force, the halogen-halogen interaction (not to be confused with the halogen bond). In addition to the network analysis of the crystal structures of compounds 1-4, a traditional analysis, by inspection of intermolecular atom-atom geometries, is 15 compared to an independent approach based on Hirshfeld surfaces. ${ }^{9}$

For discussion purposes the structures of 1-4 will be compared to the crystal structures of the saturated compounds rac-2,6-dimethylbicyclo[3.3.1] nonane-exo-2,exo-6-diol

20 chloroacetic acid clathrate, ${ }^{4 \mathrm{~b}} \mathrm{rac}-\mathbf{5}$, and $\mathrm{rac}$ bicyclo[3.3.1] nonane-endo-2, endo-6-diol, ${ }^{6}$ rac-6, both of which crystallise with spontaneous resolution, thus forming conglomerates. Finally, the solid state structure of racbicyclo[3.3.1] nonane-2,6-dione, $r a c-7,{ }^{10}$ forming racemic

${ }_{25}$ crystals, and the solid state structure of the corresponding enantiopure compound $(+)-7,{ }^{6 a}$ will also be used as reference substances (Figure 3).

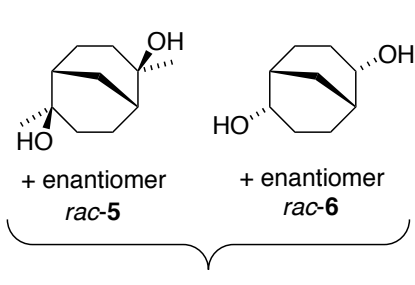

form conglomerates

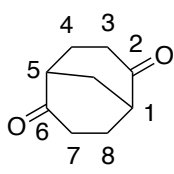

rac-7

forms racemic crystals
Fig. 3. The bicyclo[3.3.1]nonane diols $r a c-5, r a c-6$ and diones $r a c-7$ and (+)-7 used as reference compounds for the discussions in this work.

\section{Results and discussion}

Synthesis

The synthetic procedures are presented in Scheme 1. Both rac-bicyclo[3.3.1]nona-3,7-diene-endo-2,endo-6-diol, rac-1, 35 and $r a c-3,7-d i b r o m o b i c y c l o[3.3 .1]$ nona-3,7-diene-2,6-dione, rac-3, were synthesised using rac-bicyclo[3.3.1]nona-3,7diene-2,-6-dione, $\mathrm{rac}-\mathbf{2}^{11}$ as starting compound. Hence, reducing $r a c-2$ under Luche conditions afforded $r a c-1$ in $95 \%$ yield. The previous synthesis of the bromodienone $\mathrm{rac}-\mathbf{3}$ was 40 based on a bromination-elimination sequence of the saturated dienone. $^{12}$ However, we found that the synthesis of bromodienone based on a bromination-elimination protocol developed for $\alpha, \beta$-unsaturated ketones works better. Thus, in this way $\mathrm{rac}-\mathbf{3}$ was synthesized from dienone $\mathrm{rac}-\mathbf{2}$ in $65 \%$ ${ }_{45}$ yield. ${ }^{13}$ Dicyano-diene $\mathrm{rac}-\mathbf{4}$ was synthesised in accordance with the literature procedure. ${ }^{14}$
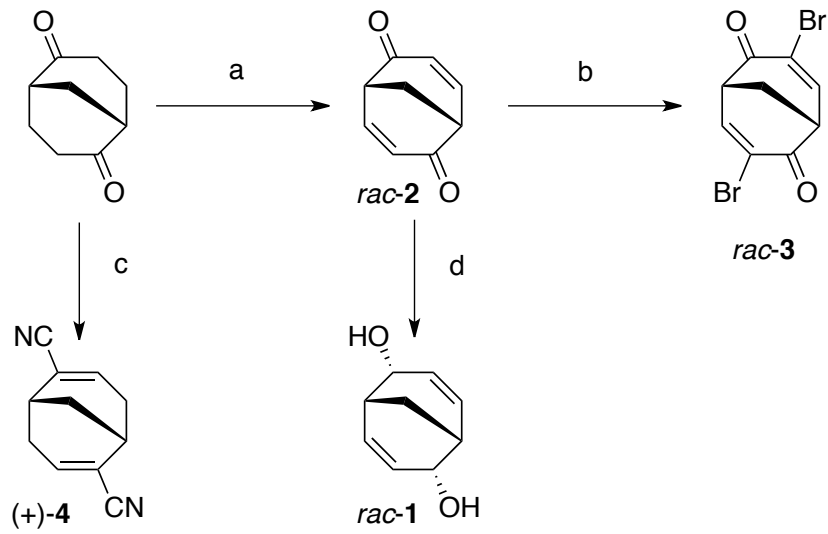

rac-3

Scheme 1. Reagents and conditions: a) i) PhSOOMe, NaH, THF ii) $50 \mathrm{Na}_{2} \mathrm{CO}_{3}, \mathrm{PhMe}, 80 \%$; b) $\mathrm{Br}_{2}, \mathrm{CCl}_{4}, \mathrm{Et}_{3} \mathrm{~N}, 65 \%$; c) i) $\mathrm{TMSCl}, \mathrm{ZnI}_{2}, \mathrm{NaCN}$, DCM ii) $\mathrm{POCl}_{3}$, pyridine, $76 \%$; d) $\mathrm{NaBH}_{4}, \mathrm{CeCl}_{3}, \mathrm{MeOH}, 95 \%$.

\section{Crystal Structure Analysis}

\section{Comparison between the unsaturated and saturated diols}

rac-Bicyclo[3.3.1]nona-3,7-diene-endo-2,endo-6-diol, rac-1. A 55 displacement ellipsoid plot of the molecular unit and the hydrogen-bond pattern of the crystal structure of the dienediol rac-1 are displayed in Figure 4. No unusual features are present at the molecular level.
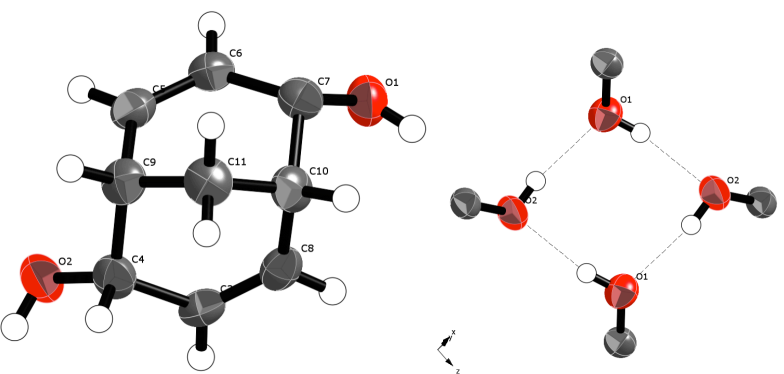

${ }_{60}$ Fig. 4 Left: A displacement ellipsoid (50\%) plot of the crystal structure of dienediol rac-1. Right: Hydrogen bond squares.

In the crystal structure, the hydrogen bonds involving the hydroxyl groups are the only ones present. Both hydroxyl groups in each molecule is involved and each hydroxyl group ${ }_{65}$ acts both as a hydrogen-bond acceptor and -donor, forming a cyclic hydrogen-bond network involving eight atoms and four molecules of $r a c-1$. The hydrogen-bonded squares shown in Figure 4 connect these dienediols into a sheet structure, cf. Figure 5, distinctively different from the 3D hydrogen bond 70 nets of the saturated diol $\mathrm{rac}-\mathbf{5}$, containing two exo-hydroxyl groups, $\left(8^{3}\right)$-eta, and $\mathrm{rac}-\mathbf{6}$, containing two endo-hydroxyl groups $\left(8^{2} .12\right)$-utg. ${ }^{6 \mathrm{a}}$ The resulting puckered sheets are close packed as displayed in Figure 6 . The topological representation of the 3 -connected $2 \mathrm{D}$ net in the crystal 75 structure of $r a c-1$ is shown in Figure 7. 


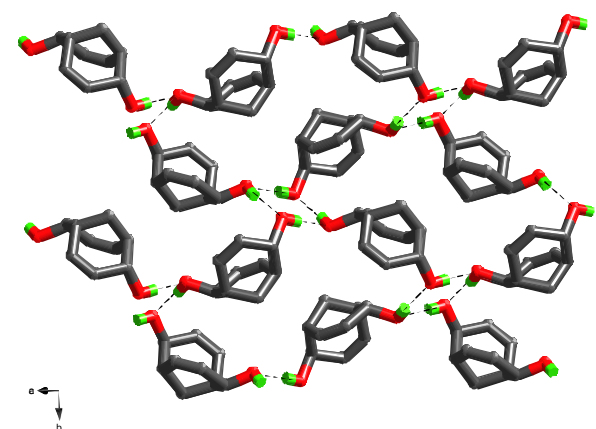

Fig. 5 The hydrogen-bonded network in the crystal structure of dienediol rac-1. Note that no $\mathrm{C}(\mathrm{sp} 2)-\mathrm{H} \cdots \mathrm{O}$ hydrogen bonds are detected.

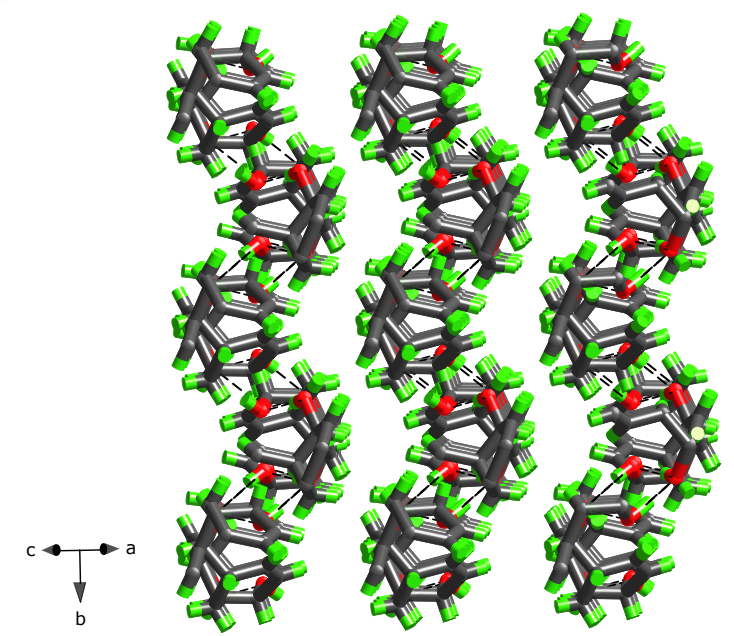

Fig. 6 A side view of the packing of the hydrogen bonded sheets of dienediol rac-1.

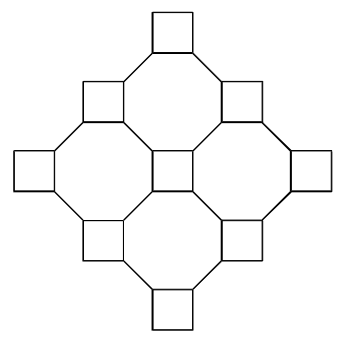

Fig. 7 The most symmetric form of the three-connected net in rac-1.

For further discussion it will be important to note that in this 10 case a racemic solution of $\mathrm{rac}-\mathbf{1}$ crystallises as a racemate, whereas $\mathrm{rac}-\mathbf{5}$ and $\mathrm{rac}-\mathbf{6}$ both crystallise as conglomerates.

\section{Comparison between the unsaturated and saturated diones}

rac-Bicyclo[3.3.1]nona-3,7-diene-2,6-dione, rac-2. A displacement-ellipsoid plot of the molecular unit and the 15 hydrogen bonds of the crystal structure of $\mathrm{rac}-\mathbf{2}$ is displayed in Figure 8 (left). No unusual features are present at the molecular level.
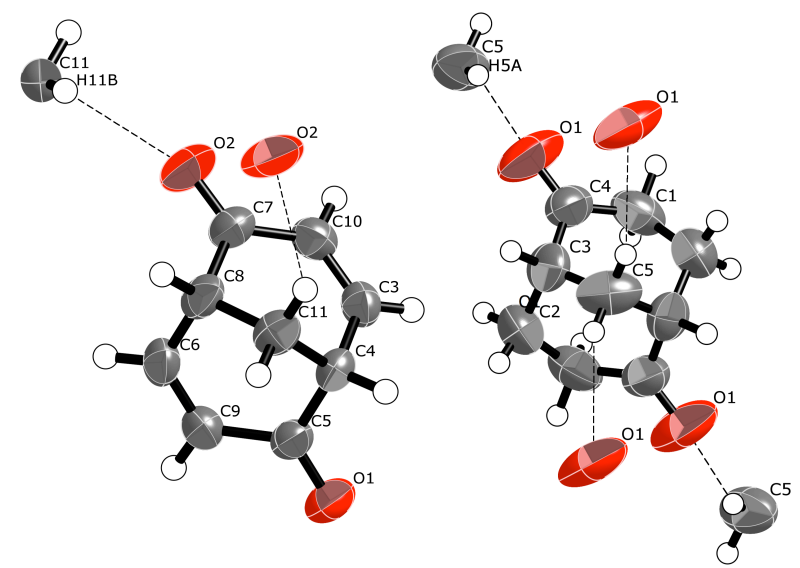

Fig. 8 Left: displacement ellipsoid (50\%) plot of the crystal structure of $20 \mathrm{rac}-\mathbf{2}$ showing also the weak hydrogen bond interactions. Right: The corresponding plot for the crystal structure of enantiopure saturated dione $(+)-7$. The hydrogen bonding between the methine hydrogen $(\mathrm{C} 9-\mathrm{H})$ and carbonyl oxygen $(\mathrm{O} 1)$ on an adjacent $r a c-2$ is not displayed for clarity. See Fig 9 for the complete view.

${ }_{25}$ The shortest intermolecular $\mathrm{O} \cdots \mathrm{H}$ interaction is between $\mathrm{H} 11 \mathrm{~B}$ residing on the bridgehead carbon $\mathrm{C} 11$ and $\mathrm{O} 2: 2.53 \AA, 3.373$ $\AA$ and the $\mathrm{OCH}$ angle being $140^{\circ}$ (Fig. 8, left). This is very similar to what was observed for the enantiomerically pure crystals of the corresponding saturated dione $(+)-7,{ }^{6 \mathrm{a}}(2.52 \AA$, $\left.303.401(2) \AA, 150^{\circ}\right)$. As can be seen by comparing the displacement ellipsoid plots of the two compounds (Figure 8), the orientations of the interactions are almost identical, except that for $r a c-2$ this connection uses only one bridgehead hydrogen atom instead of two as in $(+)-7$. Completing the 35 analogy between the crystal structure of $\mathrm{rac}^{-2}$ and $(+)-\mathbf{7}$, we would expect this intermolecular bond to occur between the enantiomers of the same absolute configuration in the crystal structure of $\mathrm{rac}-\mathbf{2}$, and this is indeed the case, giving singleenantiomer chains, or flat helices, along the $b$-axis of the 40 crystal, $50 \%$ of the chains having enantiomers of one absolute configuration of molecule rac-2 and $50 \%$ of the opposite. This indeed results in racemic crystals.

The overall crystal structure of $\mathrm{rac}-\mathbf{2}$ is displayed in Fig. 9. The $\alpha$-hydrogen atom (connected to $\mathrm{C}\left(\mathrm{sp}^{2}\right)$ ) and the adjacent 45 carbonyl oxygen atom in one of the enone systems of each molecule of $\mathbf{r a c}-\mathbf{2}$ is engaged in hydrogen-bonding with the same enone system in an adjacent molecule of $\mathrm{rac}-\mathbf{2}$, forming a cyclic hydrogen-bonding system involving eight atoms and two molecules, with the graph set notation $\mathrm{R}(2,2) 8$ of the first so level. Furthermore, the carbonyl oxygen atom of the other enone system in each $\mathrm{rac}-2$, is together with one of the bridgehead hydrogen atoms, engaged in a propagating helical hydrogen-bonding system with two other next neighbours. (different from the one involved in the first type of hydrogen${ }_{55}$ bonding network). Overall this results in a herringbone $(6,3)$ 2D net displayed in Figure 9.

Comparing the structure of unsaturated $\mathrm{rac}-\mathbf{2}$ to the saturated analogue $\mathrm{rac}-7,{ }^{10}$ we see that the latter contains, a similar $\left(2.621 \AA, 3.493 \AA, 144^{\circ}\right)$ but double $\mathrm{O} \cdots \mathrm{H}-\mathrm{C}$ ${ }_{60}$ bridgehead interaction, giving chains perpendicular to the $y-$ axis. However, if every second of the $\mathrm{R}(2,2) 8 \quad \mathrm{O} \cdots \mathrm{H}-\mathrm{C}$ interactions in $\mathrm{rac}-\mathbf{2}$ is ignored something akin to the close 
packing of rods emerge, just as for $\mathrm{rac}-7$. This illustrates the difficulty in drawing conclusions on the structure directing power of individual weak interactions.

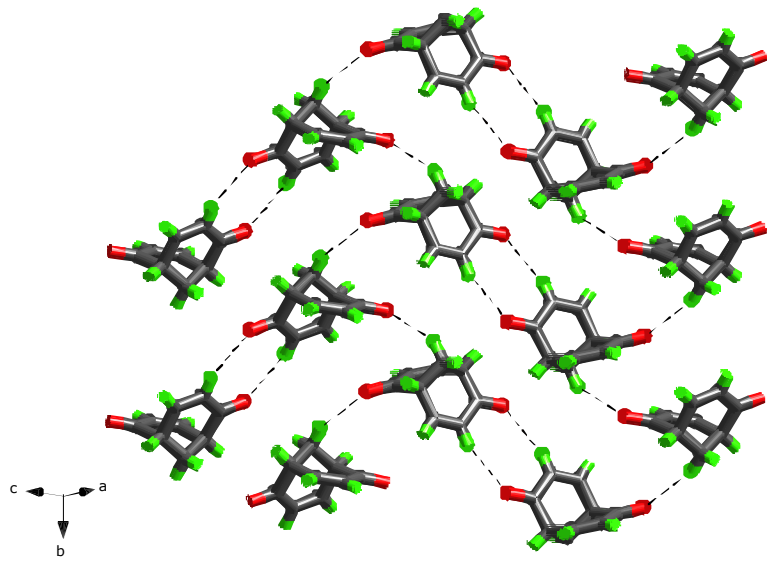

5 Fig. 9 Herringbone (6,3)-2D net formed by weak $\mathrm{O} \cdots \mathrm{H}-\mathrm{C}$ interactions in rac- 2. All hydrogen-bonding interactions are displayed.

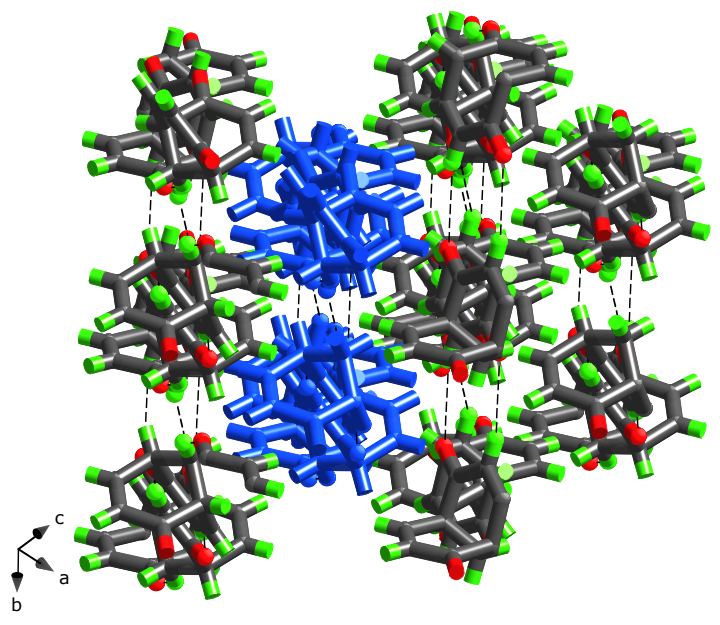

Fig. 10 The packing of the sheets in rac-2 (Fig. 9). One sheet has been highlighted in blue.

\section{${ }_{10}$ Comparison between the unsaturated bromo-ketone and the unsaturated ketones}

rac-Dibromobicyclo[3.3.1]nona-3,7-diene-2,6-dione, rac-3. Substituting each of the two hydrogen atoms in the $15 \alpha$-positions in ketone $r a c-2$ for two bromine atoms, gives compound $\mathrm{rac}-\mathbf{3}$. In $\mathrm{rac}-\mathbf{3}$, the carbonyl oxygen at carbon 2 $(\mathrm{O} 20)$ and the hydrogen atom at carbon 8 (hydrogen atom attached to $\mathrm{C} 4)$ form a cyclic $\mathrm{R}(2,2) 10$ hydrogen-bonding network with the carbonyl oxygen atom at carbon $6(\mathrm{O} 21)$ and 20 the hydrogen atom atom at carbon 4 (hydrogen atom attached to $\mathrm{C} 15$ ) in an adjacent molecule of rac-3 (Figure 11). This hydrogen-bonded system contains 10 atoms and each molecule of rac-3 forms two such interactions. Concerning the bromines, each bromine atom is engaged in halogen${ }_{25}$ halogen bonding ${ }^{15}$ to another neighbouring molecule (Figure 11). Thus, the weak self-complimentary $\mathrm{R}(2,2) 8$ bonding pattern involving the carbonyl oxygen atom and the $\alpha$ hydrogen atom attached to a $\mathrm{C}\left(\mathrm{sp}^{2}\right)$ that was seen between two adjacent molecules in the crystal structure of $\mathrm{rac}-\mathbf{2}$, is now 30 disabled being replaced by another weak interaction - the halogen-halogen interaction.

This interaction has been described based on the angles $\theta_{1}$ and $\theta_{2}\left(\theta_{1}=\mathrm{C}^{1}-\mathrm{Br}^{1 \cdots} \mathrm{Br}^{2}, \theta_{2}=\mathrm{Br}^{1 \cdots} \mathrm{Br}^{2}-\mathrm{C}^{2}\right)$ as either "type-I" with $\theta_{1}=\theta_{2}$ and usually $>110^{\circ}$, or "type-II" with $\theta_{1}=180^{\circ}$ 35 and $\theta_{2}=90^{\circ}$. In the general case, both types arise because of the polarisation (anisotropy) of the bromine electron density ${ }^{16}$ and the basic geometry of this interaction can be readily explained by a simple circular 2D model of the $\mathrm{Br}$ atom with a positive segment traversing the centre from side to side and 40 smaller negatively polarised segments on top and at the bottom. ${ }^{15 \mathrm{~b}}$ (Typically for this interaction, the $3 \mathrm{D}$-electrostatic potential energy iso-surface looks much like a stuffed olive.)

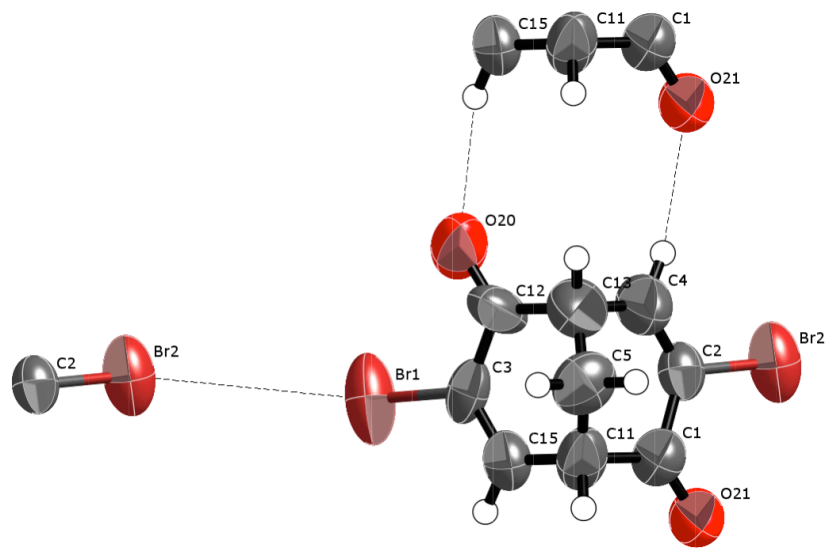

Fig. 11 A displacement ellipsoid (50\%) plot of the crystal structure of rac $\mathbf{- 3}$ also indicating the major intermolecular interactions.

The $\mathrm{Br}{ }^{\cdots} \mathrm{Br}$ interactions in this structure (3.901 $\AA, \theta_{1}=$ $145^{\circ}, \theta_{2}=140^{\circ}$ ) are rather typical examples of a type $\mathrm{I}$ interaction as these have also somewhat longer $\mathrm{Br}{ }^{\cdots} \mathrm{Br}$ distances than the type II. ${ }^{15 \mathrm{~b}}$ Possibly, the self-complimentary ${ }_{50} \mathrm{O} \cdots \mathrm{H}-\mathrm{C}$ weak hydrogen bonds are reinforced by the inductive effect of the bromine atom as they are not observed in any of the other compounds in the series and because the interaction seems somewhat stronger $\left(2.436 \AA, 3.282 \AA, 143^{\circ}\right)$. Finally, these $(4,4) 2 \mathrm{D}$ nets, shown in Figure 12, are interconnected by ${ }_{5} \mathrm{Br}{ }^{*} \mathrm{H}-\mathrm{C}$ intermolecular forces in the expected geometrical range, 3.2-3.3 $\AA$ and $130-134^{\circ}$. (A plot of $\mathrm{Br}^{\cdots} \mathrm{H}-\mathrm{C}$ geometry data from the $\mathrm{CSD}^{17}$ is included in the Supplementary material as Figure S1.)

At the molecular level, the introduction of the bromine 60 atoms means that the molecules takes on a much more specific "cleft" shape as the distance from the "peak" (C5 in Figure 11) to the base is increased from around $2.8 \AA\left(\mathrm{C} 11^{\cdots} \mathrm{C} 10\right.$ distance in $\mathrm{rac}-2)$ to $4.6 \AA(\mathrm{C} 5 \cdots \mathrm{Br}$ distance in $\mathrm{rac}-3)$. Based on this one might argue that the crystal structure of $\mathrm{rac}-\mathbf{3}$ ${ }_{65}$ could better be described as a close packing of these "cleft" molecules in the solid state than being a result of a few particular intermolecular interactions. The space filling plot in Figure 13 indicates that this may be the case. 


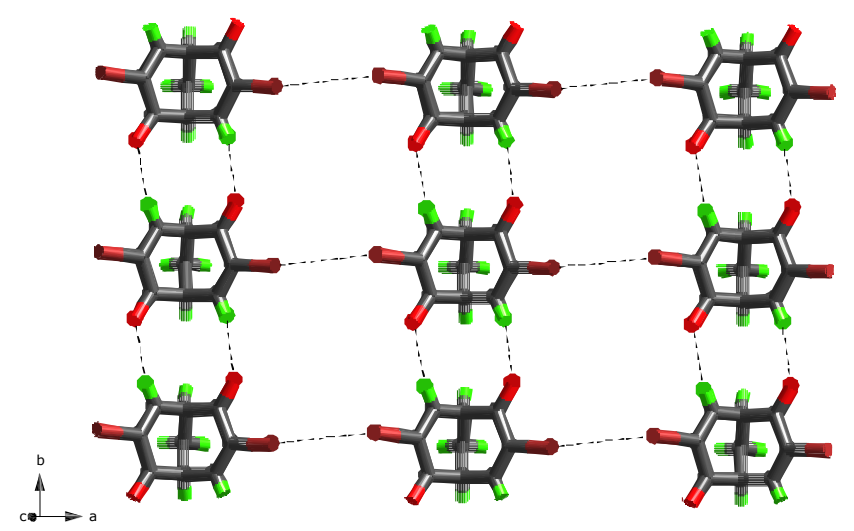

Fig. 12 The 2D net in the crystal structure of rac-3.

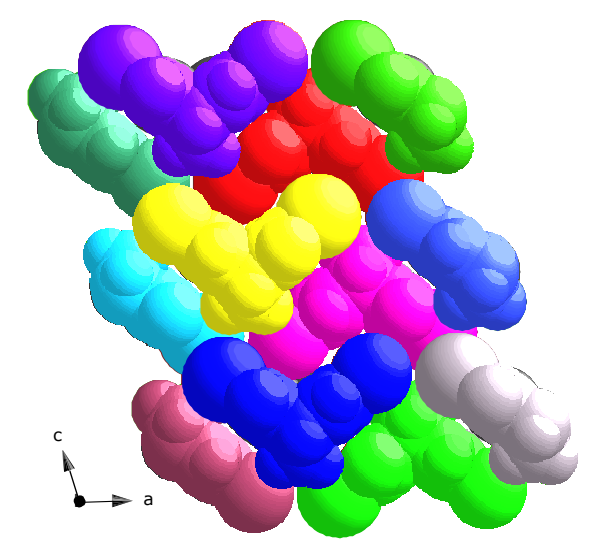

Fig. 13 Space filling plot of the crystal structure of $r a c-3$ in the $a c$-plane.

${ }_{5}$ Comparison between the racemic and optically pure unsaturated nitrile

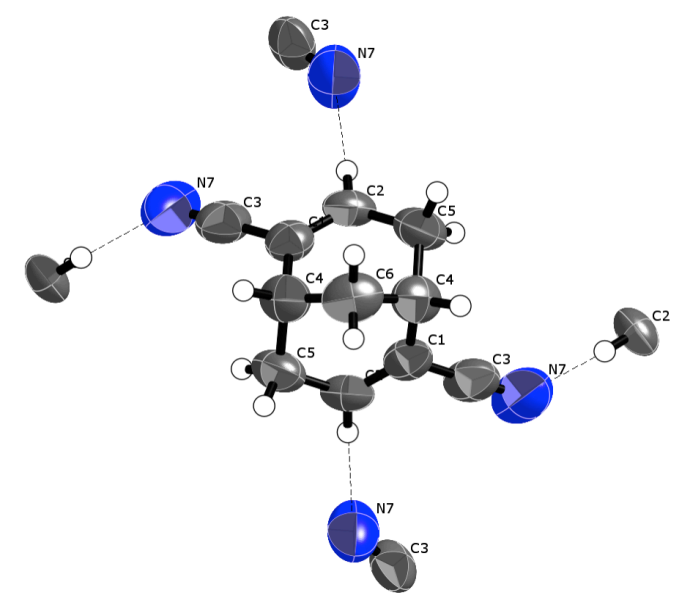

Fig. 14 A displacement ellipsoid (50\%) plot of the crystal structure of (+)-4 indicating also the shortest intermolecular contacts.

(+)-Bicyclo[3.3.1]nona-2,6-diene-2,6-dicarbonitrile, $(+)-4$ The molecular unit of enantiomerically pure $(+)-4$ with the shortest $\mathrm{C} \equiv \mathrm{N} \cdots \mathrm{H}$ interactions indicated in the crystal structure 15 is plotted in Figure 14. The nitrile nitrogen atom is a hydrogen-bond acceptor to one $\alpha$-hydrogen atom (attached to $\left.\mathrm{C}\left(\mathrm{sp}^{2}\right)\right)$ in an adjacent molecule $(+)-\mathbf{4}$ and one endo- $\beta$ - hydrogen atom (attached to $\mathrm{C}\left(\mathrm{sp}^{3}\right)$ ) in another adjacent molecule $(+) \mathbf{- 4}$, creating again a $\mathrm{R}(2,2) 10$ cyclic hydrogen20 bonding system.

Again, these shortest interactions $\left(\mathrm{C} \equiv \mathrm{N} \cdots \mathrm{H}-\mathrm{C}\left(\mathrm{sp}^{2}\right)\right)(2.561$ $\left.\AA, 3.487 \AA 141^{\circ}\right)$ are within the expected intermolecular attractive region (see plot in Figure S2) and defines a $2 \mathrm{D}$ 25 network in which also the second shortest $\left(\mathrm{C} \equiv \mathrm{N} \cdots \mathrm{H}-\mathrm{C}\left(\mathrm{sp}^{3}\right)\right)$

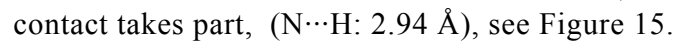

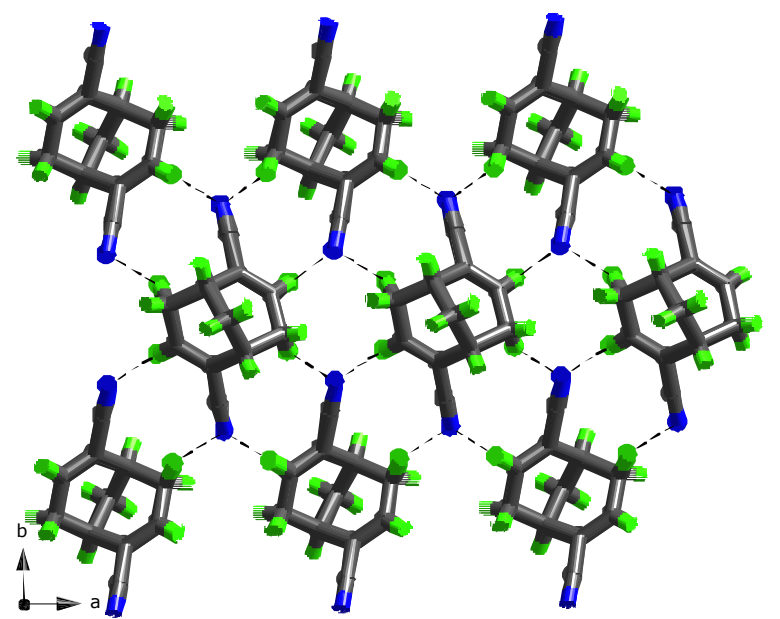

Fig. 15 The 2D net in the crystal structure of (+)-4 defined by the shortest $\mathrm{C} \equiv \mathrm{N} \cdots \mathrm{H}$ contacts (two types).

Fig. 16 Packing of (+) -4 with one 2D sheet in red.

35 The crystal structure of the racemate, $\mathrm{rac}-4,{ }^{10}$ displays the same kind of weak hydrogen bonds, giving the same 2D pattern, and consequently cell parameters that are very close. Possibly, this is due to the fact that the hydrogen bond acceptor $(\mathrm{CN})$ is protruding far away $(2.6 \AA)$ from the chiral 40 core of the molecule, making the same kind of hydrogen bonds possible in the two cases.

\section{Hirshfeld surface analysis}

The analysis of a crystal structure using only a few selected geometric data is at most approximate and at worst 45 misleading. A remedy has been proposed based on the analysis of so called Hirshfeld surfaces, ${ }^{9}$ a boundary surface of a molecule in a structure. At each point of this surface one can measure the distances to the closest atom on the inside $\left(d_{\mathrm{i}}\right)$ and outside $\left(d_{\mathrm{e}}\right)$ of the surface. The so generated 2D plots ${ }_{50}$ provide not only a unique fingerprint of the environment surrounding each type of molecule in a structure, but also hint on various types of intermolecular interactions. For example, hydrogen bonds $\mathrm{D}-\mathrm{H} \cdots \mathrm{A}$ tend to generate a number of points where the $\mathrm{H}$ and $\mathrm{A}$ atoms are the closest. If the molecule 55 hydrogen bonds to itself, two distinct traces will be seen in the plot, one with the $\mathrm{H}$ inside the surface and A outside, giving short $d_{\mathrm{e}}$ values and long $d_{\mathrm{i}}$ values starting at $d_{\mathrm{e}}+d_{\mathrm{i}}$ equal to 
the shortest $\mathrm{H} \cdots \mathrm{A}$ distances, and vice versa.

It is important to note that there is no new information generated by the Hirshfeld surfaces and the various variables that can be mapped on it, but they do have the advantage of 5 providing a single picture of all the intermolecular atom-atom interactions in a structure.

The following examination was made more or less independently of the classical analysis in the preceding section and we can therefore briefly comment on the added

10 value of the Hirshfeld approach.

rac-Bicyclo[3.3.1]nona-3,7-diene-endo-2,endo-6-diol, rac-1. In this analysis we use the fingerprint option in CrystalExplorer $^{\mathrm{TM}}$ that for each point on the Hirshfeld surface plots the closest distance to an atom outside the surface $\left(d_{\mathrm{e}}\right)$ 15 against the closest distance to an atom inside the surface $\left(d_{\mathrm{i}}\right)$.

We have compared the crystal structure of the racemic dienediol, $r a c-1$, with that of the rac-bicyclo[3.3.1]nonaneendo-2,endo-6-diol, $r a c-6$, earlier prepared and analysed by us $^{7}$ that forms a hydrogen-bonded 3D-net upon ${ }_{20}$ crystallisation. In Figure 17 we see that the most prominent features of the crystal structures of diol $\mathrm{rac}_{-6} \mathbf{6}$ and the dienediol $r a c-1$ are the same, namely the symmetric spikes for the $\mathrm{H} \cdots \mathrm{O}$ interaction extending towards the lower left of the diagrams, accounting for $18 \%(r a c-6)$ and $20 \%(r a c-1)$ of the ${ }_{25}$ points on the Hirshfeld surface. However, in the crystal structure of $r a c-1$ there is clearly an additional feature manifested in the "wings" symmetrically extending down to $\left(d_{\mathrm{e}}=1.6, d_{\mathrm{i}}=1.1\right)$. As CrystalExplorer also allows the mapping of individual atom-atom contacts it is easy to identify this as 30 short $\mathrm{C}-\mathrm{H} \cdots \mathrm{C}$ contacts, (Figure 17, right) and subsequent inspection of the surface and the crystal structure identifies this as the specific interaction between the hydrogen on $\mathrm{C} 4$ and the $\mathrm{sp}^{2}$ hybridised $\mathrm{C} 3,(9.5 \%$ of the surface points), reinforcing the network interaction in the $b$-direction. Thus a 35 distinguishing feature of the crystal structure of $\mathrm{rac}-1_{1}$ compared to the one of $r a c-6$ is that the $\mathrm{sp}^{2}$ hybridised carbon atoms open up the hydrogen covered bicyclononane framework to render the $\mathrm{C} \cdots \mathrm{H}$ interactions accessible.

rac-Bicyclo[3.3.1]nona-3,7-diene-2,6-dione, $r a c-2$. The crystal 40 structure of the dienedione, $r a c-2$, was in a similar way compared to the crystal structures of the corresponding saturated racemic dione, $\mathrm{rac}-7$, and the enantiopure saturated dione $(+)-7$, both earlier discussed by us, ${ }^{6 a}$ and the resulting plots are shown in Figure 18.
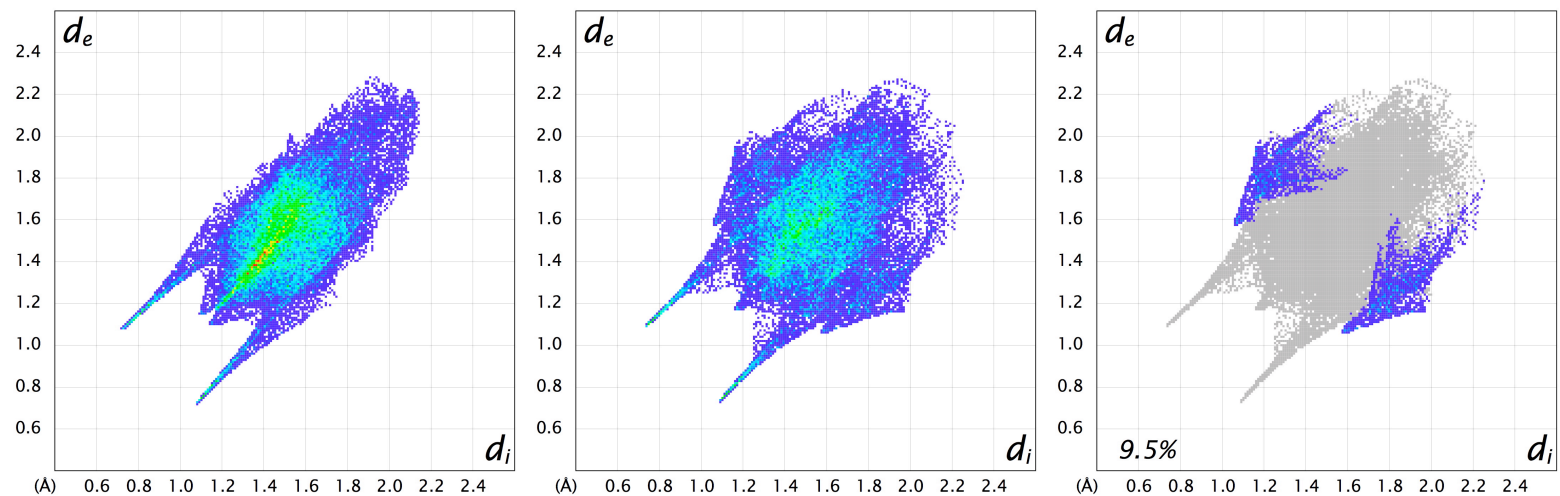

Fig. 17 Hirshfeld fingerprint plot of rac-bicyclo[3.3.1]nonane-endo-2,endo-6-diol, rac-6 (left), rac-bicyclo[3.3.1]nona-3,7-diene-endo-2,endo-6-diol, rac-1 (middle), and highlighted $\mathrm{CH}$ interactions in rac-1 (right, blue, other interactions faded to gray). Note that these plots display all points on the Hirshfeld surface and the colour coding (red many points, blue few points, at each $\mathrm{x}, \mathrm{y}$, pair) is identical in all plots.
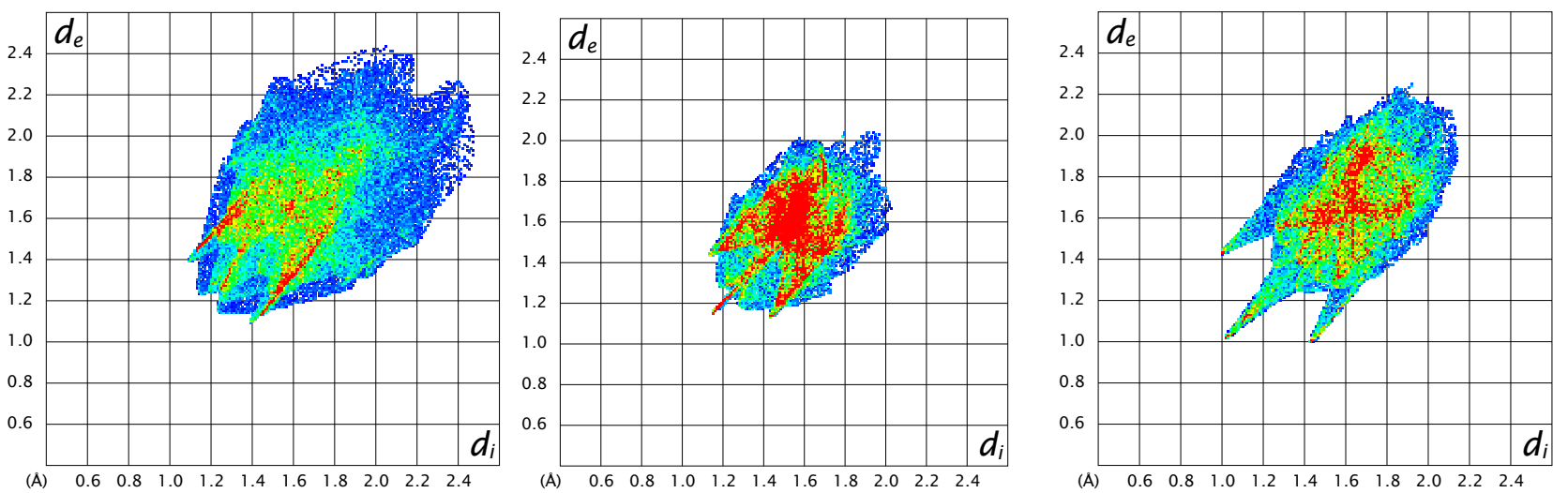

Fig. 18 Hirshfeld fingerprint plots of unsaturated rac-bicyclo[3.3.1]nona-3,7-diene-2,6-dione, rac-2 (left), compared to the plots of the corresponding saturated $\mathrm{rac}$-bicyclo[3.3.1]nonane-2,6-dione, $r a c-7$ (middle), and the structure of the enantiopure saturated dione (+)-7 (right). See text for further explanation.

Immediately we can notice the more diffuse character of the $(10.4 \%)$, but also to $\mathrm{C} \cdots \mathrm{O}(1.6 \%)$ and $\mathrm{C} \cdots \mathrm{C}(2 \%)$ interactions ${ }_{55}$ diene based framework and again, this corresponds to $\mathrm{C} \cdots \mathrm{H}$ made possible by the $\mathrm{sp}^{2}$ carbons. The spikes at the flanks 
indicate weak $\mathrm{C}-\mathrm{H} \cdots \mathrm{O}$ hydrogen bonds and are somewhat more pronounced in the enantiopure crystals of $(+)-7$, Figure 18 , right, as is the (repulsive) $\mathrm{H} \cdots \mathrm{H}$ contact demonstrated by the diagonal spikes. The larger area of $(+)-7$ spreading up to higher 5 values of $d_{e}$ indicate a less dense structure compared to rac-7.

As observed in the "manual" analysis, we can see both similarities and differences in these plots, but perhaps the more diffuse points in the plots for $\mathrm{rac}-\mathbf{2}$ and $\mathrm{rac}-\mathbf{7}$ compared to (+)7 indicate that the close packing motif is important for these 10 compounds.

rac-3,7-Dibromobicyclo[3.3.1] nona-3,7-diene-2,6-dione, rac3 . For this compound we have plotted the Hirshfeld surface mapped with the normalised contact distance $d_{\text {norm }}$, Fig. 19, indicating distances shorter than the van der Waals radii in red.

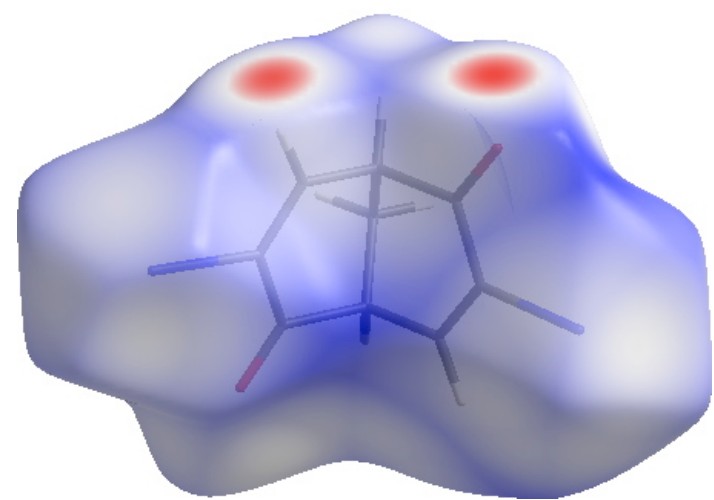

Fig. 19 Hirshfeld surface mapped with the normalised contact distance $d_{\text {norn }}$ for dibromodienedione $r a c-3$

The self-complementary weak hydrogen bonds found in the manual analysis is clearly seen as two bright red spots, and this 20 interaction covers $24.8 \%$ of the Hirshfeld surface. The Br...Br interactions also discussed in the preceding section are not found in this plot, and although present in the fingerprint plot in Fig. 20, they cover only $6 \%$ of the surface, so in this respect both $\mathrm{Br} \cdots \mathrm{O}(8.5 \%)$, and especially $\mathrm{Br} \cdots \mathrm{H}(34.0 \%)$ seem to be 25 more important

In this case, however, it is important to understand that the Hirshfeld analysis does not take angular information into account, and as especially the larger halogen atoms $\mathrm{Br}$ and I have a pronounced anisotropy, responsible for the weak 30 halogen-halogen interactions found in $\mathrm{rac}-\mathbf{3}$ the use of only Hirshfeld plots may actually be misleading in such cases.

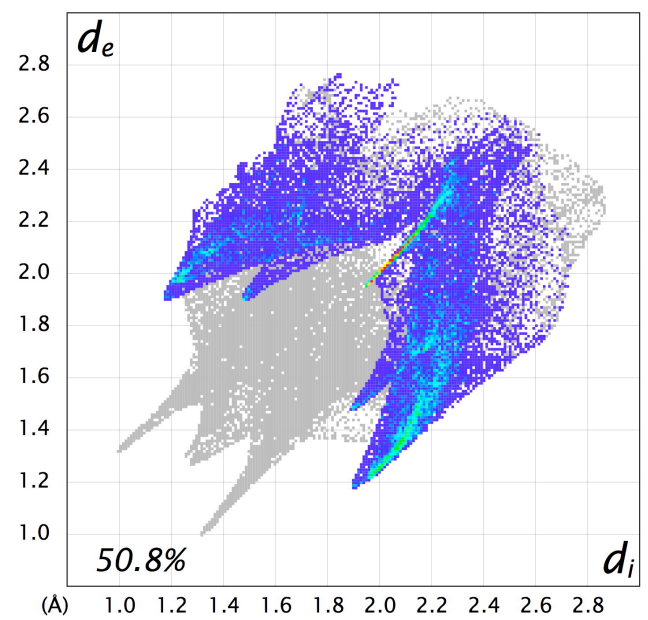

Fig. 20 Hirshfeld fingerprint plot with bromide interactions to other atoms highlighted for dibromodienedione rac-3.

$(+)-B i c y c l o[3.3 .1]$ nona-2,6-diene-2,6-dicarbonitrile $\quad(+)-4$. The structure of $(+)-\mathbf{4}$ was compared to the racemic counterpart, rac-4, by their respective Hirshfeld surfaces mapped with the normalised contact distance $d_{\text {norm }}$ shown in Fig. 21 . While we in 40 the preceding section judged these two structures as similar, these plots on the contrary indicate important differences. Thus, while the spots are all in the same places, supporting some qualitative similarity between the structures, the brighter spots in $(+)-4$ indicate that one particular $\mathrm{C}-\mathrm{H} \cdots \mathrm{N}$ interaction is substantially stronger than the other interactions present in this compound.
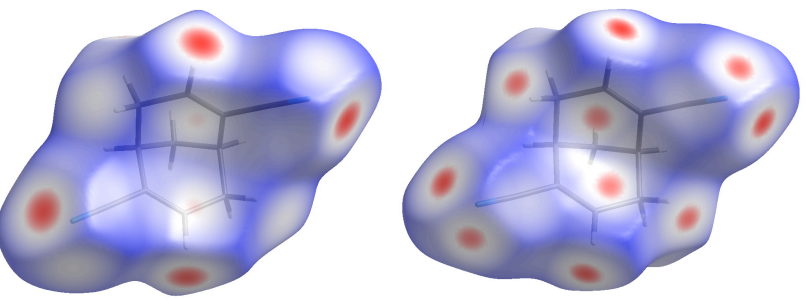

Fig. 21 Hirshfeld surfaces mapped with the normalised contact distance $d_{\text {norm }}$ for enantiopure dicyanodiene, (+)-4 (left) and racemic dicyanodiene rac-4 (right). Red colour indicates short contacts, blue colour no contacts.

\section{Network formation and chirality}

In our earlier work on $\mathrm{BCN}$ network compounds we noted that spontaneous resolution (conglomerate formation) was ${ }_{55}$ concomitant with chiral nets in the crystals. We summarise these results and the work presented here in Table 1.

Prior to formulating a tentative statement based on these data, we note two problems that limit the value of our discussion. Firstly, this analysis is restricted to $\mathrm{BCN}$ structures, and a more ${ }_{60}$ comprehensive search of the literature will be necessary to reach more general conclusions about conglomerate formation. Secondly, we have not explored the possibility of polymorphism of these compounds; perhaps a broader search of crystal growth conditions will lead to other polymorphs suggesting other ${ }_{65}$ conclusions. 
Table 1. The preferred mode of crystallisation from a racemic solution for 1,2 and 5-7 indicating what kind of networks are formed for both racemic and enantiopure crystals (if available).

\begin{tabular}{|c|c|c|c|c|}
\hline Compound & Racemate & Conglomerate & $\begin{array}{c}\text { Conglomerate } \\
\text { network }\end{array}$ & $\begin{array}{l}\text { Racemate } \\
\text { network }\end{array}$ \\
\hline dienediol 1 & $\mathrm{X}$ & & - & 2D, achiral \\
\hline $\operatorname{diol} 5$ & & $\mathrm{X}$ & 3D, chiral & - \\
\hline diol 6 & & $\mathrm{X}$ & $3 \mathrm{D}$, chiral & - \\
\hline dienedione 2 & $\mathrm{X}$ & & - & $2 \mathrm{D}$, achiral \\
\hline dione 7 & $\mathrm{X}$ & & - & $1 \mathrm{D}$, achiral \\
\hline
\end{tabular}

We would like to suggest the following hypothesis that obviously needs further experimental data to be verified or falsified: Conglomerate formation is advantageous when the strongest intermolecular interactions present have the geometric $c_{5}$ requirements to form a chiral net. Note that there seems to be 10 nothing forbidding an achiral network, such as the diamond (dia) net, to adopt a chiral conformation (embedding).

This agrees with the data in Table 1, as the 2D net of $\mathrm{rac}-\mathbf{1}$ is achiral and the crystals racemic, whereas for $\mathrm{rac}_{\mathbf{5}} \mathbf{5}$ and $\mathrm{rac}-\mathbf{6}$ the networks are chiral and they crystallize as conglomerates.

15 The enantiopure saturated dione, $(+)-7$, gives a chiral 3D net. However the more dense structure of $\mathrm{rac}_{-7}$ gives crystals having a higher melting point and thus a thermodynamically more stable product, in this case a racemic crystal structure, This observation further suggests that strong hydrogen-bonding 20 motifs, such as hydroxyl groups, are a prerequisite for spontaneous resolution for this particular compound class.

Other chiral motifs formed by strong hydrogen bonds, like helices and their stacking, have also been implicated in conglomerate formation, ${ }^{18 a}$ and a related discussion of chiral 25 coordination networks appeared in $2005^{18 \mathrm{~b}}$. Thus the idea that an intrinsic chiral motif in the overall crystal packing is important in obtaining spontaneous resolution is not entirely new.

\section{Summary and Conclusions}

30 Upon introducing double unsaturation in the skeleton of $\mathrm{BCN}$ derivatives new hydrogen-bond donors are introduced. The basic unsaturated BCN skeleton was modified by the introduction of different functional groups, leading to compounds 1-4. Each of these four unsaturated molecules has a 35 different hydrogen-bonding pattern. Their solid-state structures were analysed in detail and when possible a network descriptor was assigned. More specifically, upon introducing double unsaturation, the resulting crystal structures display weak hydrogen bonds to the hydrogen atoms attached to $\mathrm{C}\left(\mathrm{sp}^{2}\right)$. This 40 is clearly seen in the difference of the Hirshfeld plots of dienediol $\mathrm{rac}-\mathbf{1}$ compared to diol $\mathrm{rac}-\mathbf{6}$. Similar effects can be seen in dienedione rac-2 compared to dione rac-7. By introducing bromine atoms into $\mathrm{rac}-\mathbf{2}$ to give the dibromodienone, $r a c-3$, another, less known intermolecular

${ }_{45}$ force, the halogen-halogen interaction could be observed. The crystal structures have been subjected to independent analysis by inspection of intermolecular atom-atom geometries and by Hirshfeld surfaces, proving the utility of this latter methodology. For example, in the Hirschfeld analysis we could so show that the intermolecular forces in $(+)-\mathbf{4}$ are dominated by a few strong $\mathrm{C}-\mathrm{H} \cdots \mathrm{N}$ interactions, whereas the corresponding X-ray Crystallography racemic structure, $r a c-4$, displays a larger number of weaker hydrogen bonds.

The unsaturated diol derivative displays 2D sheet structure, where the corresponding saturated compound displays chiral 3D networks and conglomerate formation. This prompted us to call attention to the possible connection between conglomerate formation and chiral nets, but we are reluctant to draw any firm conclusions based on our limited study. However, formation of chiral $3 \mathrm{D}$ nets seems to be dependent on the presence of strongly hydrogen-bonding motifs, such as hydroxyl groups, but a wider set of compounds from the $\mathrm{BCN}$-family are needed to confirm this hypothesis which is based solely on the present observations.

\section{Experimental}

\section{General procedures and materials.}

Compounds $\mathbf{r a c}-\mathbf{2}$ and $(+)-\mathbf{4}$ were prepared according to literature. ${ }^{10,11}$ All commercially available reagents were purchased from Sigma Aldrich and used as received. ${ }^{1} \mathrm{H}$ and ${ }^{13} \mathrm{C}$ NMR spectra were recorded in $\mathrm{CDCl}_{3}$ on a Bruker Avance 400 or a Bruker DR400 spectrometer working at $400 \mathrm{MHz}$. Chemical shifts are given in ppm downfield from TMS using residual solvent peaks as reference. Elemental analyses were performed by H. Kolbe, Mülheim an der Ruhr, Germany.

rac-Bicyclo[3.3.1]nona-3,7-diene-endo-2,endo-6-diol, rac-1.

To a solution of $\mathrm{rac}-2(50 \mathrm{mg}, 0.34 \mathrm{mmol}), \mathrm{CeCl}_{3} \cdot 7 \mathrm{H}_{2} \mathrm{O}(0.25$ g, $0.68 \mathrm{mmol})$ in $\mathrm{MeOH}(1.7 \mathrm{~mL}) \mathrm{NaBH}_{4}$ was added in portions ( $4 \times 6.5 \mathrm{mg}, 0.68 \mathrm{mmol})$ over a period of two min. at ambient temperature. The reaction mixture was stirred for $20 \mathrm{~min}$. and then quenched with $\mathrm{HCl}(1 \mathrm{~mL}, 1 \mathrm{M})$ and concentrated in vacuo to a volume of approximately $1 \mathrm{~mL}$. Brine $(5 \mathrm{~mL})$ was added and the mixture was extracted with diethyl ether $(5 \times 5 \mathrm{~mL})$. ${ }_{35}$ The combined organic phases were dried over $\mathrm{MgSO}_{4}$ and concentrated in vacuo yielding white solid crude material. The product was isolated using flash chromatography affording 49 $\mathrm{mg}$ of $\mathrm{rac}-1$ in $95 \%$ yield. ${ }^{1} \mathrm{H}-\mathrm{NMR}: \delta=5.88(\mathrm{ddd}, \mathrm{J}=10.2,5.4$, $1.8 \mathrm{~Hz}, 2 \mathrm{H}), 5.75(\mathrm{~m}, 2 \mathrm{H}), 4.50(\mathrm{~m}, 2 \mathrm{H}), 2.60(\mathrm{~m}, 2 \mathrm{H}), 1.83$ $(\mathrm{m}, 2 \mathrm{H}), 1.60(\mathrm{bs}, 2 \mathrm{H}) ;{ }^{13} \mathrm{C}-\mathrm{NMR}: \delta=132.3,128.2,78.9,42.1$, 29.2; Anal. calcd for $\mathrm{C}_{9} \mathrm{H}_{12} \mathrm{O}_{2}: \mathrm{C} 71.03 ; \mathrm{H}$ 7.95. Found: $\mathrm{C}$ $70.92 ; \mathrm{H} 7.84$

rac-3,7-Dibromobicyclo[3.3.1]nona-3,7-diene-2,6-dione, rac-3.

Bromine (0.32 g, $2.0 \mathrm{mmol})$ was added dropwise to an ice-cold solution of di(enone) $\mathrm{rac}-2(0.15 \mathrm{~g}, 1.0 \mathrm{mmol})$ in $\mathrm{CCl}_{4}(10 \mathrm{~mL})$ and the mixture was stirred at $0{ }^{\circ} \mathrm{C}$ for $1 \mathrm{~h}$. To this mixture $\mathrm{NEt}_{3}$ was added $(0.22 \mathrm{~g}, 2.2 \mathrm{mmol})$ slowly and the mixture was stirred at room temperature overnight forming a white precipitate. The reaction mixture was diluted with $\mathrm{CH}_{2} \mathrm{Cl}_{2}$, washed with a saturated solution of sodium thiosulfate, water and brine, dried over $\mathrm{Na}_{2} \mathrm{SO}_{4}$ and evaporated in vacuo. The residue was crystallized from a $\mathrm{CH}_{2} \mathrm{Cl}_{2} / \mathrm{CCl}_{4}$ mixture to afford $152 \mathrm{mg}(50 \%)$ of $\mathrm{rac}-\mathbf{3}$ as a slightly yellow solid. An additional amount of product $(10-15 \%)$ could be obtained from the mother liquor by flash chromatography.

${ }^{1} \mathrm{H}-\mathrm{NMR}: \delta 7.70(\mathrm{~d}, \mathrm{~J}=6.85,2 \mathrm{H}), 3.68(\mathrm{~m}, 2 \mathrm{H}), 5.26(\mathrm{t}, \mathrm{J}=$ $2.90,2 \mathrm{H}) ;{ }^{13} \mathrm{C}-\mathrm{NMR}: \delta 185.1,145.7,122.0,48.2,34.2$; Anal. calcd for $\mathrm{C}_{9} \mathrm{H}_{6} \mathrm{Br}_{2} \mathrm{O}_{2}$ : C 35.33; H 1.98. Found: C 35.63; H 2.14 . 
Crystals suitable for X-ray diffraction analysis of $\mathrm{rac}-\mathbf{1}$ were grown from a saturated chloroform solution at $4{ }^{\circ} \mathrm{C}$ over night. Crystals of $\mathrm{rac}-\mathbf{3}$ were obtained by slowly letting a layer of heptane diffuse into a saturated solution of $r a c-\mathbf{3}$ in chloroform and crystals of $\mathrm{rac}-\mathbf{2}$ were obtained by slow evaporation of a petroleum ether $\left(40-60{ }^{\circ} \mathrm{C}\right)$ solution. Intensity data were collected at $293 \mathrm{~K}$ with an Oxford Diffraction Xcalibur $3^{45}$ system using $\omega$-scans and Mo-K $\alpha(\lambda=0.71073 \AA) .{ }^{19} \mathrm{CCD}$ data were extracted and integrated using Crysalis RED. ${ }^{20}$ The 10 structures were solved using direct methods and refined by fullmatrix least-squares calculations on $\mathrm{F}^{2}$ using SHELXTL 5.1.1 ${ }^{50}$ Non-H atoms were refined with anisotropic displacement parameters. Hydrogen atoms were constrained to parent sites, using a riding model. Crystal data and details about data 15 collection are given in Table 1 . All crystallographic data ares available in CIF format, see ESI and CCDC reference numbers 768529-768532. Three letter codes for the network topologies were taken from O'Keeffe et al. ${ }^{22}$

Table 2 Parameters for data collection and structure refinement of racemic ${ }^{60}$ $201,2,3$ and $(+)-4$.

\begin{tabular}{|c|c|c|c|c|}
\hline & $r a c-1$ & $r a c-2$ & $r a c-3$ & $(+)-4$ \\
\hline Chemical formula & $\mathrm{C}_{9} \mathrm{H}_{12} \mathrm{O}_{2}$ & $\mathrm{C}_{9} \mathrm{H}_{6} \mathrm{Br}_{2} \mathrm{O}_{2}$ & $\mathrm{C}_{9} \mathrm{H}_{8} \mathrm{O}_{2}$ & $\mathrm{C}_{11} \mathrm{H}_{10} \mathrm{~N}_{2}$ \\
\hline Formula weight & 152.19 & 305.96 & 148.16 & $170.21 \quad 65$ \\
\hline Crystal system & monoclinic & monoclinic & monoclinic & orthorhombic \\
\hline Space group & $\mathrm{P} 2{ }_{1} / \mathrm{n}$ & $\mathrm{P} 2{ }_{1} / \mathrm{c}$ & $\mathrm{P} 2{ }_{1} / \mathrm{c}$ & $\mathrm{P} 2{ }_{1} 2{ }_{1} 2$ \\
\hline$a / \AA$ & $9.2834(7)$ & $10.3618(7)$ & $6.8088(3)$ & $7.3655(5)$ \\
\hline$b / \AA$ & $8.5265(5)$ & $6.6849(5)$ & $7.4891(4)$ & $11.7786(9)$ \\
\hline$c / \AA$ & $9.8621(7)$ & $14.6052(11)$ & $14.8396(8)$ & $5.5546(4) 70$ \\
\hline$\beta /{ }^{\circ}$ & $93.062(6)$ & $107.353(7)$ & $100.854(5)$ & 90 \\
\hline Volume $/ \AA^{3}$ & $779.52(9)$ & $965.62(12)$ & $743.16(7)$ & $481.89(6)$ \\
\hline Z & 4 & 4 & 4 & 2 \\
\hline$\rho_{\text {calc }} / \mathrm{Mg} \mathrm{m}^{-3}$ & 1.288 & 2.105 & 1.324 & 1.173 \\
\hline$\mu / \mathrm{mm}^{-1}$ & 0.090 & 8.356 & 0.093 & 0.071 \\
\hline $\begin{array}{l}\text { No. of reflections } \\
\text { collected }\end{array}$ & 4831 & 5869 & 7381 & 3059 \\
\hline $\begin{array}{l}\text { No. of independent } \\
\text { reflections }\end{array}$ & 1373 & 1678 & 2627 & 519 \\
\hline$\theta$ range $/^{\circ}$ & $2.94-25.02$ & $2.92-25.02$ & $2.80-33.09$ & $3.26-25.0280$ \\
\hline $\mathrm{R}$ (int) & 0.0692 & 0.0502 & 0.0175 & 0.0238 \\
\hline No. of parameters & 102 & 118 & 100 & 60 \\
\hline Goodness-of-Fit & 0.890 & 0.873 & 1.029 & 0.918 \\
\hline $\mathrm{R} 1(I>2 \sigma(I))$ & 0.0394 & 0.0710 & 0.0412 & 0.0310 \\
\hline wR2 (all data) & 0.0633 & 0.2735 & 0.1337 & $0.0727 \quad 85$ \\
\hline
\end{tabular}

\section{Acknowledgements}

This work was supported by Nordforsk via the Nordic-Baltic ${ }_{25}$ Network in Crystal Engineering and Supramolecular Materials and the Swedish Research Council. We thank the Knut and Alice Wallenberg Foundation for funding the diffractometer and ${ }^{5}$ the Swedish Research Links program for a travel grant to LÖ.

\section{Notes and references}

${ }_{30}{ }^{a}$ Address, Centre for Analysis and Synthesis, Department of Chemistry, Lund University, P. O. Box 124, SE-221 00 Lund, Sweden. Fax: +4646 2228209; Tel: 4646222 0000; E-mail: ola.wendt@organic.lu.se, CarlJohan.Wallentin@organic.lu.se,Magnus.Johnson@organic.lu.se, Kenneth.Warnmark@organic.lu.se

${ }_{35}{ }^{b}$ Address, Dept Organic Chemistry, University of Vilnius, Naugarduko 24, Vilnius 03225, Lithuania. Fax: +370-5-2330987; Tel: +370-682-63092; Email:edvinas.orentas@chf.vu.lt,Eugenijus.Butkus@chf.vu.lt,
' Address, Department of Chemistry, Faculty of Applied Sciences, Cape Peninsula University of Technology, email: bathorin@cput.ac.za ${ }^{d}$ Address, Dept. of Chemical and Biological Engineering, Chalmers University of Technology, SE-41296 Göteborg, Sweden. Fax: +46 31772 3858; E-mail: ohrstrom@chalmers.se,

$\dagger$ Electronic Supplementary Information (ESI) available: [details of any supplementary information available should be included here]. See DOI: $10.1039 / \mathrm{b} 000000 \mathrm{x} /$

\$ Footnotes should appear here. These might include comments relevant to but not central to the matter under discussion, limited experimental and spectral data, and crystallographic data.

(1) Zefirov, N. S. Russ. Chem. Rev. (Engl. Transl.), 1975, 44, 196-211 1975, 44, 413.

(2) (a) Fukuyama, Y.; Kuwayama, A.; Minami, H. Chem. Pharm. Bull. 1997, 45, 947-949. (b) Fukuyama, Y.; Kuwayama, A.; Minami, H. Phytochemistry 1998, 49, 853-857.

(3) Wang, R.; Yan, H.; Tang, H. C. Acta Pharmacologica Sinica 2006, 27, 1 .

(4) (a) Ung, A. T.; Bishop, R.; Craig, D. C.; Dance, I. G.; Scudder, M. L. Chem. Mat. 1994, 6, 1269 (b) Ung, A. T.; Gizachew, D.; Bishop, R.; Scudder, M. L.; Dance, I. G.; Craig, D. C. J. Am. Chem. Soc. 1995, 117, 8745(c) Stoncius, S.; Butkus, E.; Zilinskas, A.; Larsson, K.; Öhrström, L.; Berg, U.; Wärnmark, K. J. Org. Chem. 2004, 69, 5196(d) Stoncius, S.; Orentas, E.; Butkus, E.; Öhrström, L.; Wendt, O. F.; Wärnmark, K. J. Am. Chem. Soc. 2006, 128, 8272 (e) Nguyen, V. T.; Bishop, R.; Craig, D. C.; Scudder, M. L. Supramol. Chem. 2001, 13, 103.

(5) Bishop, R. Acc. Chem. Res. 2009, 42, 67.

(6) (a) Wallentin, C.-J.; Orentas, E.; Johnson, M. T.; Butkus, E.; Wendt, O. F.; Öhrström, L.; Wärnmark, K. CrystEngComm 2009, 11, 1837. (b) V. T. Nguyen, I. Y. H. Chan, R. Bishop, D. C. Craig and M. L. Scudder, New J. Chem. 2009, 33, 1736-1741

(7) Öhrström, L.; Larsson, K. Molecule-Based Materials. The structural Network Approach. Elsevier, Amsterdam, 2005.

(8) Johansson, R.; Öhrström, L.; Wendt, O. F. Cryst. Growth \& Design 2007, 7, 1974.

(9) (a) 1. M. A. Spackman and J. J. McKinnon, Crystengcomm, 2002, 378392. (b) 1.J. J. McKinnon, M. A. Spackman and A. S. Mitchell, Acta Cryst. B., 2004, 60, 627-668 (c) Spackman, M. A.; Jayatilaka, D. Crystengcomm 2009, 11, 19.

(10)Quast, H.; Becker, C.; Geissler, E.; Knoll, K.; Peters, E. M.; Peters, K.; von Schnering, H. G. Liebigs Ann. 1994, 109.

11) Orentas, E.; Bagdžiūnas, G.; Berg, U.; Zilinskas, A.; Butkus, E. Eur. J. Org. Chem. 2007, 4251

(12) T. A. Klimova; M. M. Krayushkin; V. V. Sevostyanova; S. S. Novikov; Karpenko, N. F. Izv. Akad. Nauk SSSR, Ser. Khim. 1975, 1565- 1969, Chem. Abstr., 83 1975, 147411g.

(13) Ogasawara, M.; Okada, A.; Nakajima, K.; Takahashi, T. Org. Lett. 2009, $11,177$.

(14) H. Quast, H.; Witzel, M.; Peters, E.-M.; Peters, K; von Schnering, H. G. Liebigs Ann., 1995, 725.

(15) (a) Awwadi, F. F.; Willett, R. D.; Peterson, K. A.; Twamley, B. Chem.

90 Eur. J. 2006, 12, 8952(b) Ghazzali, M.; Langer, V.; Lopes, C.; Eriksson, A.; Öhrström, L. New J. Chem. 2007, 31, 1777.

(16)(a) Reddy, C. M.; Kirchner, M. T.; Gundakaram, R. C.; Padmanabhan, K. A.; G. R. Desiraju Chem. Eur. J. 2006, 12, 2222(b) Desiraju, G. R.; Parthasarathy, R. J. Am. Chem. Soc. 1989, 111, 8725(c) Pedireddi, V. R.; D. S. Reddy; B. S. Goud; D. C. Craig; Rae, A. D.; Desiraju, G. R. J. Chem. Soc. Perkin Trans. 2 1994, 2353.

(17) Allen, F. H. Acta Crystallogr. 2002, B58, 380.

(18) (a) K. Kinbara, Y. Hashimoto, M. Sukegawa, H. Nohira and K. Saigo, J. Am. Chem. Soc., 118, 1996, 3441-3449. (b) A. Johansson, M. Håkansson and S. Jagner, Chem. Eur. J., 2005, 11, 5311-5318.

(19) Crysalis CCD; Oxford Diffraction Ltd. Abingdon, Oxfordshire, UK, 2005 ,

(20) Crysalis RED Oxford Diffraction Ltd. Abingdon, Oxfordshire, UK, 2005 ,

55 (21) Sheldrick, G. M. Acta Crystallogr. 2008, A64, 112.

(22)(a) M. O'Keeffe, O. M. Yaghi and S. Ramsden, Reticular Chemistry Structure Resource, Australian National University Supercomputer Facility, 2011, http://rcsr.anu.edu.au/ (b) M. O'Keeffe, M. A. Peskov, S. 
Ramsden and O. M. Yaghi, Acc. Chem. Res., 2008, 41, 1782-1789. 